\title{
CONSUMO E A ESTETIZAÇÃO DA VIDA COTIDIANA: UMA PERSPECTIVA ACERCA DA PUBLICIDADE E DOS GAMES
}

\author{
Eneus Trindade ${ }^{1}$ \\ Clotilde Perez ${ }^{2}$
}

A Revista Signos do Consumo, nesta edição de 2015, traz a reflexão sobre a estetização da vida cotidiana, privilegiando dois caminhos expressivos: a publicidade e os games. Nesse sentido, busca dar acesso as reflexões decorrentes de pesquisas, prioritariamente aquelas que acontecem nos programas de pós-graduação no país e no exterior, na área da Comunicação e nas suas relações interdisciplinares com a Cultura, Consumo e Tecnologias.

Assim, o primeiro artigo intitulado "O cotidiano fantástico na propaganda de Havaianas: o comercial televisivo como tecnologia do imaginário", de Juliana Tonin, Professora Adjunta do Programa de pós-graduação em Comunicação Social da PUCRS, Larissa Azubel, Doutoranda na PUCRS, Gabriela Kurtz e Karina Pereira Weber, ambas Mestrandas na PUCRS, apresenta a reflexão acerca do papel do comercial televisivo como uma tecnologia do imaginário contemporâneo, em sua estimulação para o conhecimento de novas referências, potencializando assim, também novas representações. Para expressar seu caminho analítico, o autor selecionou dois anúncios das sandálias Havaianas, icônica marca brasileira, onde foi possível compreender a perspectiva fantástica adotada e sua potência expressiva.

O segundo artigo de autoria de Maria Ogécia Drigo, professora do Programa de Pós-graduação em Comunicação e Cultura da Uniso, Universidade de Sorocaba e de Clotilde Perez, do PPGCOM - Programa de Pós-graduação em Ciências da Comunicação da ECA - USP, aborda as temáticas da marca e da publicidade circunscritas às reflexões acerca da maturidade adulta. Como as marcas comunicam seus posicionamentos quando buscam relacionar-se com os adultos idosos? Quais

\footnotetext{
${ }^{1}$ Professor Livre Docente do Departamento de Relações Públicas, Propaganda e Turismo da ECA/USP. Docente do PPGCOM/ECA/USP na área de teoria e pesquisa em comunicação e Vice-coordenador do Grupos de Estudos Semióticos em Comunicação, Cultura e Consumo CNPq/ECA/USP. Possui pósdoutorado em Antropologia Visual pela Universidade Aberta de Portugal. Doutor e Mestre em Comunicação pela ECA/USP. E-mail: eneustrindade@usp.br

${ }^{2}$ Professora Livre Docente em Ciências da Comunicação do Departamento de Relações Públicas, Propaganda e Turismo da ECA/USP. Docente do PPGCOM/ECA/USP na área de interfaces sociais da comunicação. Coordenadora dos Grupos de Estudos Semióticos em Comunicação, Cultura e Consumo $\mathrm{CNPq} / \mathrm{ECA} / \mathrm{USP}$. Possui pós-doutorado em Comunicação pela Universidade de Murcia-Espanha. Doutora em Comunicação e Semiótica pela PUC-SP, Mestre em Administração pela PUC-SP. E-mail: cloperez@terra.com.br
} 
Consumo e a estetização da vida cotidiana: uma perspectiva acerca da publicidade e dos games

de Eneus Trindade e Clotilde Perez

valores comunicam? Conseguem ressonância nesse público? Essas e outras questões encontram acolhimento e direcionamento no presente artigo, que é mais uma produção decorrente da pesquisa de pós-dourado levada a cabo por Maria Ogécia Drigo, com supervisão de Clotilde Perez.

A "Organização curricular de cursos superiores de Publicidade: um olhar brasileiro sobre a oferta americana", de Gino Giacomini Filho, professor do Programa de Pós-Graduação em Comunicação da Universidade São Caetano do Sul e também da ECA - USP, apresenta e discute a oferta curricular americana para cursos superiores de Publicidade por meio da discussão conceitual acerca da formação e também pelo estudo de caso da Boston University e da University of Illinois at Urbana-Champaign. Os resultados apontam que tais ofertas são estruturadas, diferenciadas, e mostram contribuições relevantes para a experiência brasileira, ainda que questões culturais e históricas nos diferenciem consideravelmente.

Os artigos na sequência têm em comum a temática dos games, o que já evidencia a relevância desta produção cultural no âmbito da Comunicação, do Consumo e tantas outras regionalidades científicas como Educação, Psicologia e Filosofia. Vejamos cada um deles a seguir.

Arlete dos Santos Petry, pós-doutora pela ECA USP, com estágio na Universidade de Toronto, apesenta o artigo "Consumo de videogames: algumas preferências e motivações para jogar". O texto trata de responder quais são as preferências e as motivações para o consumo de jogos digitais na atualidade. Para tanto, parte do estudo realizado com uma amostra de 182 jogadores estudantes universitários e de entrevistas respondidas por 5 pesquisadores da área. A pesquisa direciona para a existência de tendências relacionadas a idade, traços de personalidade, atividade laboral, entre outras. Interessante reflexão para aqueles que buscam refletir e planejar ações mercadológicas e mercarias no âmbito do consumo de games.

“Games: entretenimento, mídia e cultura”, de Valdenize Leziér Martyniuk, pósdoutora pela ECA - USP e professora da PUC SP, em conjunto com Mauro Maia Laruccia, professor do programa de Pós-graduação em Comunicação e Cultura da Uniso e da PUC SP, apresentam no texto a reflexão sobre os jogos eletrônicos como fenômeno midiático privilegiado na contemporaneidade. O objetivo do artigo é explicitar as possibilidades de pesquisa e de análise, baseadas nas especificidades desse objeto. Os autores discutem as implicações das relações promovidas entre o jogo e o jogador, bem 
Consumo e a estetização da vida cotidiana: uma perspectiva acerca da publicidade e dos games

de Eneus Trindade e Clotilde Perez

como entre o jogador e outros sujeitos do entorno, resultando em interações da ordem da programação, da estratégia, da sensibilidade e do acidente. As proposições de pesquisa têm como referência a teoria semiótica de Greimas e seus seguidores e nos estudos do ciberespaço e das mídias audiovisuais. Os jogos, então, emergem como exemplo típico para entender a construção de sentidos no ambiente social da atualidade.

Em “Perspectivas ontológicas dos games no século XXI", Luís Carlos Petry do Programa de Pós-graduação em Tecnologias da Inteligência e Design Digital, da PUC SP, apresenta as relações existentes entre o conceito de desenvolvimento de games e metaversos, a partir das discussões e contextualizações realizadas por pesquisadores do digital no que tange a presença de conceitos ontológicos em sua constituição e processo. $\mathrm{O}$ autor situa o conceito de ontologia digital e sua incidência na pesquisa dos metaversos e games. Em seguida apresenta algumas ideias normativas sobre a questão, relacionando-as a proposta de uma análise que leve em conta os pressupostos ontológicos que estão presentes na conceitualização e no desenvolvimento de um game. A partir de uma delimitação provisória do conceito de Worldbuilding (enquanto conceito de formação de mundo no campo dos games) organiza dois casos modelos. Finalmente, indica a importância que um pensar orientado ontologicamente pode desempenhar, não somente para uma compreensão mais contextualizada dos games e metaversos, mais igualmente para aqueles que se engajam em seus processos de concepção e desenvolvimento.

Para finalizar esta edição da Signos do Consumo, Alhen Rubens Damasceno, doutorando do PPGCom ECA - USP, nos oferece a resenha do livro de Gilles LIPOVETSKY e SERROY, intitulado "A estetização do mundo: viver na era do capitalismo artista”, editado pela Companhia das Letras neste ano. Lipovetsky é parte da bibliografia de disciplinas e projetos de pesquisa em Comunicação nas interfaces com as Ciências Humanas, em diferentes Universidades e grupos de investigação, tanto no Brasil, quanto no exterior. Nesta obra a reflexão se dá prioritariamente no foco da estetização do mundo por meio das marcas e, consequentemente, do sistema publicitário que é seu propulsor.

Boa leitura a todos,

Os Editores

SIGNOS DO CONSUMO, SÃO PAULO - V.7, N.1, 2015. P. 1-3, JUL. 2015 